\title{
Syllable as a synchronization mechanism
}

$\mathrm{Yi} \mathrm{Xu}$

Dept of Speech, Hearing and Phonetic Sciences, University College London, UK

https://doi.org/10.36505/ExLing-2017/08/0003/000305

\begin{abstract}
Despite being highly intuitive and widely recognized, syllable continues to be a controversial notion. It is argued here that a resolution may lie in recognizing that speech is a highly skilled motor activity with a core problem shared with other motor skills: how to reduce degrees of freedom (DOF) to the extent that makes its central nervous control possible. The most effective way of reducing DOF is to synchronize multiple articulatory movements, and the syllable serves exactly this function for speech. This synchronization hypothesis also offers resolutions to coarticulation and many other unsettled problems, and has implications for motor control in general.
\end{abstract}

Key words: synchronization, target approximation, edge synchronization

\section{Introduction}

The nature of the syllable remains a mystery to this day: "although nearly everyone can identify syllables, almost nobody can define them" (Ladefoged 1982: 220). Existing proposals (e.g., Browman \& Goldstein 1992, MacNeilage 1998) are not able to answer some of the most basic questions about the syllable: a) Why are there syllables? b) Do syllables have clear phonetic boundaries? c) Do segments have definitive syllable affiliations? Without clear answers to these questions, many other issues about speech also remain unresolvable, including, in particular, coarticulation.

\section{Syllable as a synchronization mechanism}

This article is a brief introduction of a synchronization hypothesis that can address all three questions mentioned above. The overarching proposal is that syllable is a temporal coordination mechanism whose function is to synchronize multiple articulatory movements so as to make speaking possible. The coordination involves three basic mechanisms: target approximation, edge synchronization and tactile anchoring.According to this hypothesis, speech encodes information by generating variations in phonetic (segmental, tonal and phonational) properties in quick succession, which requires concurrent articulatory movements toward multiple underlying targets (target approximation). The central nervous control of the concurrent movements is made possible by synchronizing the onsets and offsets of the movements (edge synchronization) to critically reduce degrees of freedom (DOF).

ExLing 2017: Proceedings of 8th Tutorial and Research Workshop on Experimental Linguistics, 19-22 June, Heraklion, Crete, Greece 
And tactile sensation during the closed phase of each syllable provides alignment references for the synchronization of movements (tactile anchoring).
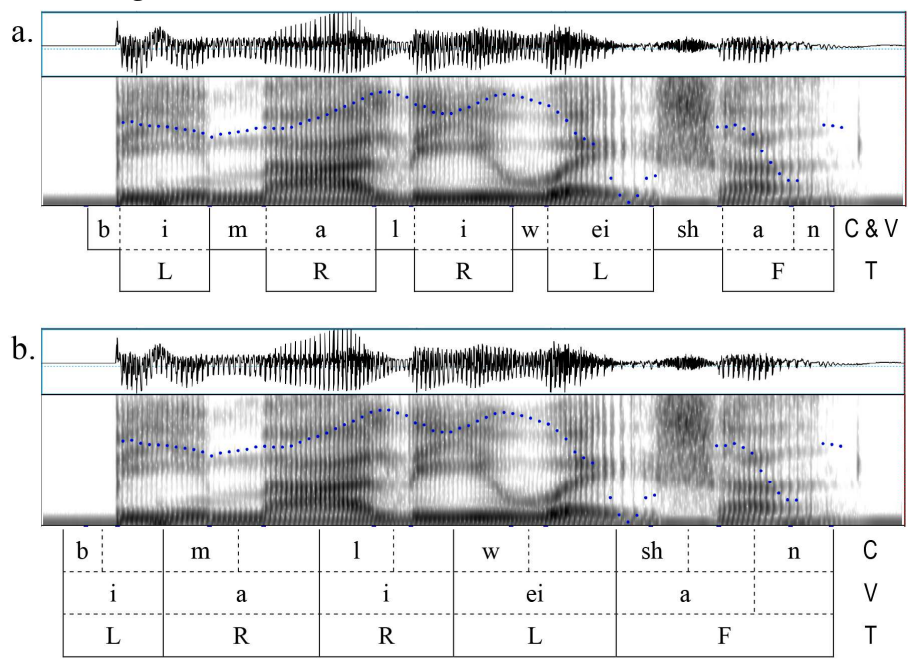

Figure 1. Spectrogram of the Mandarin phrase “比麻黎偽善” /bǐ má lì wěi shàn/ [more hypocritical than $\mathrm{Ma} \mathrm{Li}$ ], with broad phonetic transcriptions. In both panels, $\mathrm{C}, \mathrm{V}$ and $\mathrm{T}$ stands for consonant, vowel and tone. The segmentation in a. is conventional, while that in $\mathrm{b}$. is based on the synchronization hypothesis.

A direct consequence of synchronization hypothesis is a major change in the acoustic segmentation of the syllable, as illustrated in Figure 1. The conventional segmentation is shown in Figure 1a, where syllable onsets are aligned to points of abrupt spectral shift corresponding to the moments of complete oral closure (with the exception of $/ \mathrm{w} /$, for which there is not even a widely-agreed segmentation). The segmentation based on the synchronization hypothesis is shown in Figure 1b, where all the segmental boundaries are shifted leftward from those in Figure 1a. These conceptual shifts are based on the target approximation principle that the onset of a segment is when the spectral pattern starts to move toward its prototypical configuration. For $/ 1 /$, for example, the onset is in the middle of the "preceding" vowel, where F1 starts to drop toward the oral closure. The leftward shift of vowel onsets is even more extensive. For example, the first /a/ now begins from the middle of the first conventional /i/ interval where F2 starts to drop toward its prototypical level; and the second /i/ begins from the middle of the conventional /a/ interval where F2 starts to rise toward its prototypical level. Thus each vowel onset is shifted leftward, across the 
conventional consonant interval, and well into the conventional interval of the preceding vowel.

The new offset of a segment is where its prototypical configuration is best approach, but not necessarily attained. For /i/, for example, it is at the peak of F2 and F3, for /a/ it is at the peak of F1 and valley of F2, and for /w/ it is at the valley of F2, where intensity is also at a minimum. For the obstruent consonants, the offset is no longer at the end of its prototypical spectral pattern (e.g., closure gap in $/ \mathrm{b} /$, nasal or lateral formants in $/ \mathrm{m} /$ and $/ 1 /$, and the frication in $/ s /$ ), but in the middle of those intervals.Furthermore, as shown in the bottom tier of Figure $1 \mathrm{~b}$, the new tone interval fully coincides with that of the entire syllable, which consists of not only the initial consonant and the nuclear vowel, but also the coda consonant, as in the case of /shàn/.

\section{Coarticulation and DOF}

A major impact of the new syllable segmentation is on the understanding of coarticulation. Because the initial movement toward a vocalic target is now viewed as the vowel proper rather than its anticipation, it is no longer considered as evidence of either long-distance anticipatory V-to-V coarticulation (Öhman 1966) or local V-to-C anticipatory coarticulation. Instead, because initial consonant and the first vowel start at the same time, they are considered as fully coproduced or coarticulated for the duration of the consonant. Also no longer needed is the notion of carryover coarticulation. Due to inertia, an articulatory gesture toward a target has to be one of moving away from its initial state, which is the end result of approaching the preceding target. Overcoming inertia therefore necessarily carries the influence of the preceding target that is no longer being executed. So, what is carried over is only its remnant effect rather than its continued articulation.

This view of coarticulation differs from both the assimilation account and gestural overlap account (Saltzman \& Munhall 1989), as illustrated in Figure 2. In panel $a$ we can see that smooth surface trajectories can be generated by strictly sequential target approximation movements. In panel $b$ the first movement is much shortened from that in panel $a$, resulting in an undershoot of the first target. Because the undershoot is due to a premature termination of the first movement, which is effectively truncated by the second movement, there is neither assimilation nor anticipation. In panel $c$, instead of truncation, the first two movements are partially overlapped via gestural blending. The resulting trajectory, however, is not very different from the one in panel $b$. More importantly, such a blending requires more degrees of freedom than sequential target approximation, as the amount of overlap and its exact location both have to be specified. 
a.

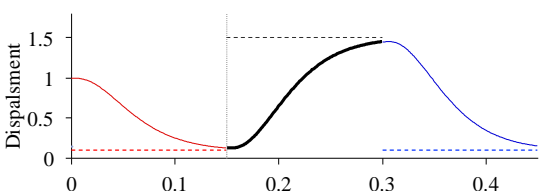

$b$.

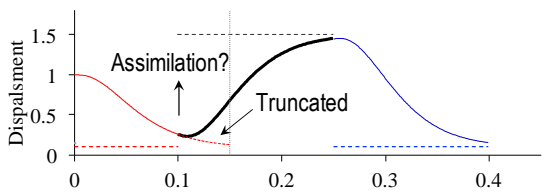

$c$.

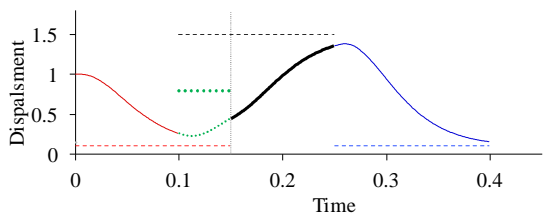

Figure 2. Sequential vs. blending target approximation. In $a$, the three movements are strictly sequential, and the vertical line divides the first two movements. In $b$, the vertical reference remains at time 0.15 , but the first movement is shortened by 0.05 unit. All the movements remain sequential, so that the first movement is truncated by the second. In $c$, the first and second movements overlap with each other by 0.05 units. The overlap is implemented by applying a blended target (horizontal green dotted line), which is the average of the first two targets. All trajectories generated by the qTA model (Prom-on et al. 2009).

\section{Tactile anchoring}

This mechanism is the final piece that completes the syllable puzzle, because it provides solutions to three critical issues. First, it explains how synchronization is achieved: by tactile feedback during the closure phase of consonants. Second, it points out that it is the edges, rather than the center of the syllable (where sonority is the highest, cf. review by Ohala 1992), that is the essence of the syllable. Finally, it predicts that syllable onset, where a maximum number of gestures can be coproduced, is a better synchronization site than syllable offset, which in turn explains why $\mathrm{CV}$ is the more prevalent syllable structure than $\mathrm{VC}$ and CVC.

\section{References}

Browman, C.P., Goldstein, L. 1992. Articulatory phonology. Phonetica 49, 155-180. MacNeilage, P.F. 1998. The frame/content theory of evolution of speech production. Behavioral and Brain Sciences 21, 499-546.

Mechsner, F., Kerzel, D., Knoblich, G., Prinz, W., 2001. Perceptual basis of bimanual coordination. Nature 414: 69-73.

Ladefoged, P. 1982. A Course in Phonetics. University of California, Los Angeles.

Ohala, J.J., 1992. Alternatives to the sonority hierarchy for explaining segmental sequential constraints. In Papers from the Parasession on the Syllable. (eds.) Chicago: Chicago Linguistic Society: 319-338.

Prom-on, S., Thipakorn, B., Xu, Y. 2009. Modeling tone and intonation in Mandarin and English as a process of target approximation. JASA 125.

Saltzman, E.L., Munhall, K.G. 1989. A dynamical approach to gestural patterning in speech production. Ecological Psychology 1, 333-382. 


\title{
Loanwords stress and intonation in Algerian Arabic
}

Ismaël Benali

CLILLAC-ARP, Université Paris Diderot, France

https://doi.org/10.36505/ExLing-2017/08/0004/000306

\begin{abstract}
This paper deals with stress and intonation patterns of loanwords in Algerian Arabic and in particular in Algiers and Oran dialects. It shows that speakers always transferred the stress pattern of Algerian Arabic in borrowed words: the final syllable is stressed if it is the only heavy syllable in the word or if it is superheavy, otherwise stress is on the penultimate syllable. Intonation patterns are also transferred to loanwords in focus and polar questions. Focus is characterized in the Algiers dialect by a falling melodic contour occurring on the last syllable. In the Oran dialect, intonation is realized with a flat or slightly rising contour. In polar question Algiers speakers produce a rising-falling contour whereas the Oran speakers produce a rising melodic contour on the last syllable.
\end{abstract}

Key words: loanword, Algerian Arabic, stress, focus, polar question

\section{Introduction}

The Algerian Arabic originates from the North African Arabic and is spoken by more than $70 \%$ of the population. It is the main vehicular language of the country. The Algiers variety is spoken in the capital in the Center of Algeria. The Oran variety is spoken in the city of Oran in the West of Algeria. In previous studies (Benali, 2008, Benali, 2016), it appeared that Algerian dialects can be identified by prosodic cues. I found also that intonation patterns which characterize Algiers and Oran varieties are marked more clearly in focus and polar question.

These two varieties have great number of borrowed words from French whereas the Oran dialect contains also Spanish loanwords. These loanwords are phonetically and morphologically modified (Gallicism) and adapted to the speakers mother tongue (Arabic or Berber) as in [si.'ni.ma] from the French word "cinéma" and in [bo.'ga.do] from the Spanish word "abogado".

In this research, I examine the place of the stress of loanwords and their prosodic realization in focus and polar question.

Few studies on stress were carried out on Algerian Arabic. Aït Oumaziane Ramadane studied the stress in the Arabic dialect of Constantine (Ait Oumeziane, 1981), Farouk Bouhadiba in the Oran dialect (Bouhadiba, 1988) and Aziza Boucherit in Algiers Arabic (Boucherit, 2006). From our study (Benali, 2015) stress falls on the final syllable if it is the only heavy syllable in the word $(\mathrm{V}$ : or $\mathrm{VC})$, or if it is superheavy $\mathrm{V}: \mathrm{C}(\mathrm{C})$

ExLing 2017: Proceedings of 8th Tutorial and Research Workshop on Experimental Linguistics, 19-22 June, Heraklion, Crete, Greece 
or VCC. Otherwise the penultimate syllable is stressed.

Few studies have dealt with the integration of loanwords into dialectal Arabic at the prosodic level. Borrowed words from French tends to lose their " tonic" accent to submit to the accentual rules of the Tunisian dialectal Arabic (Mzoughi, 2015). Naïma Fadil-Barillot presented three types of the intonative contours in the code-switching of Morroccan Arabic and French : the intonation of matrix language, the composed intonation and the recomposed intonation (Barillot, 2002).

\section{Methodology}

Recordings for this study were made in Algiers and Oran. 20 Algiers speakers and 20 Oran speakers were recorded in a quiet room using a lapel microphone. Speakers were between 22 and 30 years old. The majority of them were students and have lived all their childhood and adolescence in their respective cities.

The corpus is composed of spontaneous and read speech. The spontaneous speech utterances were extracted from a conversation between speakers and the experimenter (who was speaking a southern variety). Borrowed words and code switching were observed in this corpus.

Acoustic analysis were carried on the speech analysis/resynthesis program 'WinPitch' (Martin, 2000).

\section{Analysis}

\section{Stress in spontaneous speech}

The use of the loanword "ball" in our corpus illustrates the difference between the two dialects: Algiers speakers use the French word "ballon" and Oran speakers use the Spanish one "bola". In both cases stress is on the penultimate: ['ba.ló], ['bo.la].

Overall, Oran speakers stress the penultimate syllable as in ['sba.na] "Spain" and the final syllable when heavy and closed: [sba.'no:l] "Spanish". In the word Cervantes the stress is not on the penultimate as in Spanish but in the last syllable.

The following example shows how the loanword is morphologically integrated: ['kunt 'ntri.ni u ha.'bəst] "I trained and then I stopped" ['ntri.ni] from the French verb "entraîner", [n] and [i] are Arabic morphological marks. Stressed syllable is longer and has a rising F0.

Algiers speakers stress also the penultimate syllable as in [teks.'plo.zi] "you explode (in anger)" from the French verb "exploser". This syllable is lengthened whereas the finale syllable carries a falling F0 as in ['dza.zət 
in.'ti:k] "It went very well" from the French word "antique" in the meaning of well, good.

So Algiers and Oran speakers in loanwords stress the final syllable if it is the only heavy syllable in the word or if it is superheavy. In the other case the penultimate is stressed. Acoustic analysis shows that Algiers speakers used more F0 range to stress the syllable than the Oran speakers $(\mathrm{p}<0,0001)$ who use more vowel lengthening $(\mathrm{p}<0,0013)$.

\section{Intonation in read speech}

In the statement used for this study ['Jra kat.sã.' kat 'ba.fi] "He bought a 404 pickup", there are two loanwords [kat.sã.'kat] from the French model car "404 Peugeot" and ['ba.ji] from the French word "bachée" meaning a pickup. Only the second word is stressed on the penultimate syllable, forming an accent group. The speakers were asked to produce this statement with an emphatic focus on the last word and to produce it as a polar question.

Emphatic narrow focus is produced in the Algiers dialect by a rising contour on the stressed syllable followed by a falling contour. In the Oran dialect, this focus is realized with a flat or slightly rising contour on the stressed syllable (figure 1). In both dialects the stressed syllable is lengthened.

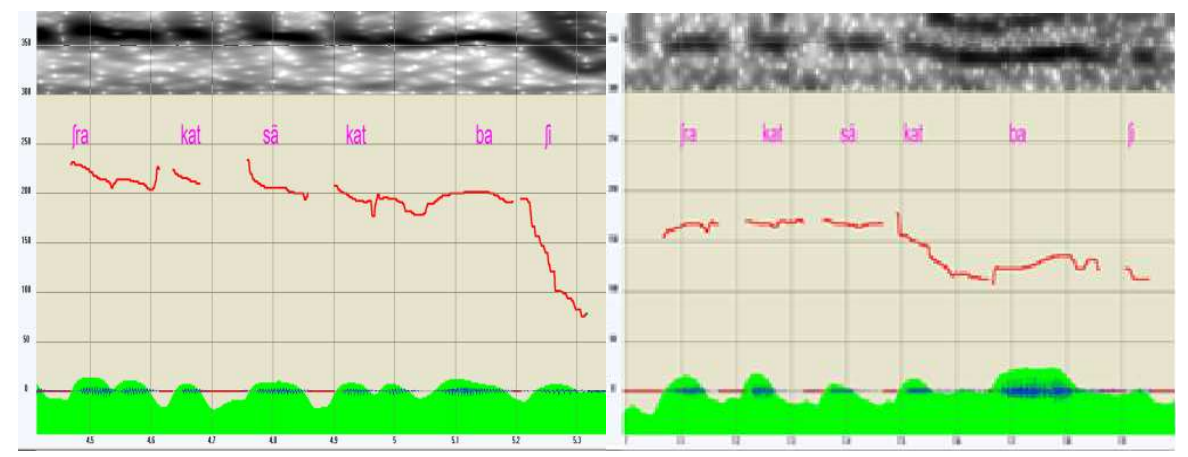

Figure 1. Emphatic narrow focus produced by Algiers (left) and Oran speakers (right).

In polar question Algiers speakers produced an amplified rising-falling contour while Oran speakers produced on the last syllable a rising contour (figure 2). 


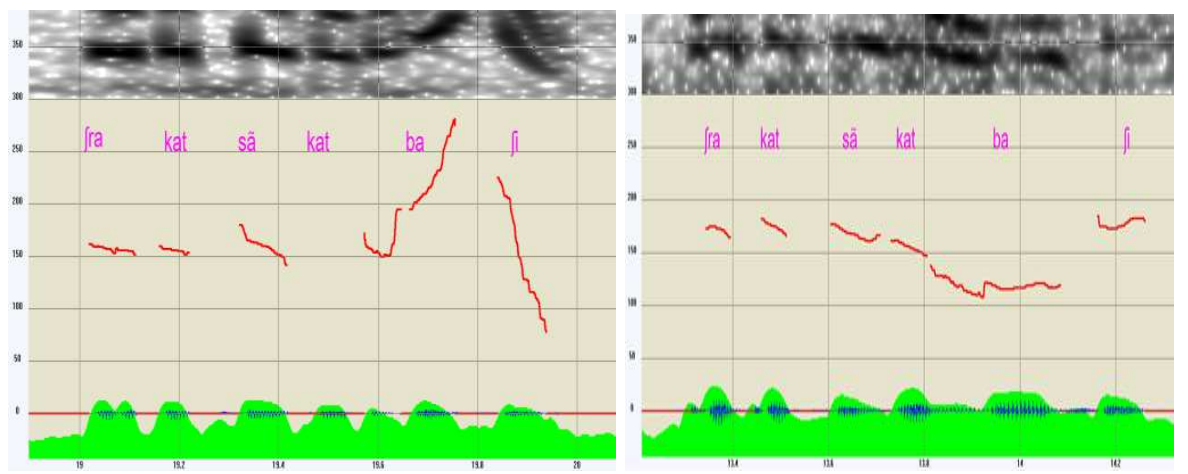

Figure 2 Polar question produced by Algiers (left) and Oran speakers (right).

These results are similar to those obtained in Algiers and Oran dialectal Arabic.

\section{Conclusion}

The results of this study show that Algerian speakers always transferred the stress pattern of Algerian Arabic to loanwords words. Intonation patterns are also transferred in focus and polar questions.

\section{References}

Aït Oumeziane, R. 1981. Le Parler Arabe de Constantine. Doctorat, Université Sorbonne Nouvelle Paris 3.

Barillot, N.F. 2002. Etude sociolinguistique et intonative de l'alternance codique arabe marocain français.

Benali, I. 2008. La question totale dans les parlers algérois et oranais. Language design: journal of theoretical and experimental linguistics, 0039-46.

Benali, I. 2015. La focalisation dans les parlers algérois et oranais: étude prosodique. Sorbonne Paris Cité.

Benali, I. 2016. The identification of two Algerian Arabic dialects by prosodic focus. ExLing 2016, 37.

Boucherit, A. 2006. Algiers Arabic. Encyclopedia of Arabic Language and Linguistics, 58-66.

Bouhadiba, F.A.N. 1988. Aspects of Algerian Arabic verb phonology and morphology. University of Reading.

Martin, Ph. WinPitch 2000: a tool for experimental phonology and intonation research. Proceedings of the Prosody 2000 Workshop, 2000.

Mzoughi, I. 2015. Intégration des emprunts lexicaux au français en arabe dialectal tunisien. Université de Cergy Pontoise. 